\title{
Solitary Fibrous Tumor of the Prostate: Case Report and Review of the Literature
}

\author{
Laurence Moureau-Zabotto $^{a}$ Bruno Chetaille $^{b}$ \\ Franck Bladou $^{\text {h }}$ Pierre-Yves Dauvergne ${ }^{g}$ Myriam Marcy $^{\text {b }}$ \\ Delphine Perrot $^{\mathrm{e}}$ Jérôme Guiramand ${ }^{\mathrm{c}}$ Anthony Sarran $^{\mathrm{d}}$ \\ François Bertucci ${ }^{e, f}$ \\ Departments of ${ }^{\mathrm{a}}$ Radiotherapy, ${ }^{\mathrm{b}}$ Pathology, ${ }^{\mathrm{c}}$ Surgical Oncology, ${ }^{\mathrm{d}}$ Radiology, and \\ ${ }^{\mathrm{e}}$ Medical Oncology, Institut Paoli-Calmettes, and ${ }^{\mathrm{f} U n i v e r s i t y ~ o f ~ M e d i t e r r a n e a, ~}$ \\ Marseille, ${ }^{\mathrm{g}}$ Clinique Rhône-Durance, Avignon, France; ${ }^{\mathrm{h}}$ Department of Urology, \\ Jewish General Hospital, Montreal, Que., Canada
}

\section{Key Words}

Prostate $\cdot$ Solitary fibrous tumor $\cdot$ Prognosis

\begin{abstract}
Solitary fibrous tumor (SFT), usually described in the pleura, is exceedingly rare in the prostate. We report a 60 -year-old man with prostatic SFT revealed by obstructive urinary symptoms, and detected by ultrasonography. Computed tomography (CT) and magnetic resonance imaging suggested a prostatic origin. CT-guided tumor biopsy diagnosed a SFT. A cystoprostatectomy was performed. Pathologic examination showed a $15-\mathrm{cm}$ tumor arising from the prostate and showing histological criteria suggestive of aggressiveness. The surgical resection margins were tumor-free. The patient was then regularly monitored and is still alive in complete remission, 28 months after surgery. In conclusion, we report a new exceptional case of prostatic SFT. We review the literature and discuss the challenging issues of misdiagnosis, prognosis and treatment.
\end{abstract}

\section{Introduction}

Solitary fibrous tumor (SFT) is a rare spindle cell neoplasm most commonly found in the pleura [1]. However, extra-pleural locations have been reported during the last two decades [2]. Their cell of origin and etiology are uncertain, but SFTs likely derive from mesenchymal fibroblastic cells. To our knowledge, the prostatic location is exceptional. It represents a clinical challenge with other spindle cell lesions of the prostate, regarding both the diagnosis and the treatment. Given its scarcity, the continued 
documentation of prostatic SFT is important. Here, we report an additional case of prostatic SFT with a 28-month follow-up, and review the literature.

\section{Case Report}

In June 2009, a 60-year-old Caucasian man without any specific personal or familial medical history presented with a 1-year history of permanent urinary frequency and urgency. The WHO performance status was 0 . His renal function and serum PSA level were normal. He underwent a pelvic ultrasonography (US), which discovered a 13-cm partially cystic well-limited pelvic tumor, located in continuation with the prostate, and associated with a dilatation of the left upper urinary system. Abdo-pelvic computed tomography (CT) revealed a 13-cm heterogeneous pelvic tumor located closely above and likely arising from the prostate, with respect to the fat interface between the mass, the posterior bladder wall and the anterior rectal wall.

The patient was referred to our hospital. Pelvic magnetic resonance imaging (MRI) confirmed the presence of a $10-\mathrm{cm}$ heterogeneous and contrast-enhanced mass, with necrosis inside, causing mass effect on seminal vesicles, with no cleavage plane with the prostate base, associated with a left ureterohydronephrosis. Otherwise, MRI showed fat interface between the mass, the posterior bladder wall and the anterior rectal wall without any sign of involvement ( fig. 1). Histological examination of CT-guided core needle biopsies revealed a spindle cell neoplasm with small, round to fusiform cells strongly expressing CD34 associated with a ramifying vascular network. The suspected diagnosis was SFT. Complete clinical and radiological screening did not detect any lymphadenopathy or distant metastasis. Serum glucose level was normal. The tumor was considered potentially completely resectable. In August 2009, the treatment consisted in a radical cystoprostatectomy with limited bilateral pelvic lymphadenectomy, and vesical reconstruction (Hautmann neobladder). No anterior rectal resection was necessary. Excision was monobloc and macroscopically complete.

Macroscopical examination of the surgical specimen showed a small prostate $(4.5 \times 4 \times 3 \mathrm{~cm})$ and a well-limited, rounded mass $(15 \times 11.5 \times 9 \mathrm{~cm})$ developed from the prostatic base. On cut section, the tumor showed zones of whorled appearance but also cystic, hemorrhagic and necrotic areas.

Microscopical analysis (fig. 2) showed a well-encapsulated lesion composed of spindle cells arranged without any particular architecture (so-called 'patternless pattern'), associated with variable amounts of collagen and a distinctive vascularization ('staghorn' vessels). Part of the tumor was developed within the prostatic base with prostatic glands in contact with tumor cells. Cellular density and mitotic count were very heterogeneous but comprised highly cellular zones and up to 4 mitoses per 10 high-power fields (HPF). By place, fibrosis was predominant and mitotic figures less frequent. There was no capsular effraction, and no vascular embolus. Immunohistochemical (IHC) analysis showed strong expression of CD34 by tumor cells, without expression of epithelial (pancytokeratin, EMA), smooth muscle (alpha-smooth actin), and Schwann cell (PS100) markers. The retained diagnosis was SFT arising from the protatic base. Moreover, an associated 7-mm prostatic adenocarcinoma was accidentally discovered in the prostatic parenchyma, distant from the capsule, Gleason $6(3+3)$, without any macro- and microscopical connection with the SFT. The ten removed pelvic lymph nodes were free of tumor.

The postoperative course was uneventful. After surgery, no adjuvant treatment was given, and the patient's clinical and radiological levels were regularly monitored. A last visit, in November 2011, twenty-eight months after the initial diagnosis, the patient was alive with excellent performance status, without any recurrence of the disease.

\section{Discussion}

SFT is rare. It is seen in patients of all ages, but most often between 50 and 70 years [1]. SFT was originally described as a serosa-associated tumor in the thoracic cavity, but in the past 20 years it has been recognized in numerous non-serosal, extrathoracic sites, including the male genitourinary tract. Prostatic SFT is extremely rare. To the 
best of our knowledge, only 21 cases have been reported to date in the English literature, as single cases $(n=12)$ [3-13] and a series of 9 cases [14]. Our case represents the first one with complete clinical, radiological and histological data and a long follow-up.

All cases are summarized in table 1 . The median age of patients at the time of diagnosis was 60 years (range 21-87). Clinical symptoms of prostatic SFTs depend on the size (pathological size ranging from 5 to $15 \mathrm{~cm}$ ) and extension of the tumor: 1 patient was asymptomatic [8], whereas all others presented non-specific urinary and/or rectal symptoms (obstruction, pelvic pressure). One case presented with macroscopical hematuria, which required an emergency hemostatic transvesical prostatectomy. Serum PSA level was normal in all cases tested, and hypoglycemia, previously reported in a few cases of serosal SFT, was not observed in the 13 informative cases. Radiological imaging was useful for the diagnosis and staging, notably to locate the initial site of tumor development, whenever possible. Indeed, these tumors may invade the neighboring structures especially in the retrovesical space, causing difficulty in determining the organ of origin. Generally, the first imaging was US, either transrectal or transabdominal. Pelvic CT and above all MRI more frequently allowed to locate the tumor and to estimate better its locoregional extension before surgery. In our case, and as previously reported [3, 7, 12], MRI findings strongly suggested a tumor origin in the prostate, followed by extension to adjacent organs (especially bladder). The proneness of pleural SFTs to be misdiagnosed is well known [15]. Given the extra-pleural and thus unusual location, prostatic SFTs are even more prone to this problem and represent one of the least commonly found spindle cell tumors on prostatic needle biopsy or transurethral resection. Differential diagnoses are numerous: they include other prostatic benign and malignant tumors, as well as SFTs and other spindle cell tumors arising from adjacent organs (bladder, seminal vesicle, rectum) then invading the prostate, such as rectal GIST. Histological diagnosis of reported cases was provided by analysis of tumor sample, either after needle biopsy (17 cases), transurethral resection ( 2 cases), or surgical resection without any prior biopsy ( 4 cases). In all cases, definitive diagnosis was done by histological and IHC examination of the surgical resection specimen. Microscopical and IHC aspects of prostatic SFTs are similar to those of non-prostatic SFTs. In 2 cases (including ours), a small associated prostatic adenocarcinoma was concomitantly accidentally discovered [14].

Regarding the prognosis, $10-20 \%$ of pleural SFTs (so-called 'malignant SFTs') behave aggressively with local invasiveness and/or recurrences, and/or occasional distant metastases $[15,16]$. Histological features used for evaluation of malignancy include large size ( $>5-10 \mathrm{~cm}$ ), high mitotic count ( $>4$ per $10 \mathrm{HPF}$ ), high cellularity, necrosis, hemorrhage, cytological atypias with pleiomorphism, and infiltrative growth pattern $[15,17]$. However, these features do not always forecast an unfavorable clinical outcome. In a large series of pleural SFTs [15], all patients with histologically benign lesions and half of those with malignant lesions (defined by the presence of one or more of the following criteria: cellularity, mitotic count, pleomorphism) were cured by simple excision. Classically, extra-pleural SFTs have a more indolent behavior and are most always defined as benign. However, some of them can display histological aggressiveness criteria and/or present local and/or metastatic relapses [2, 6, 18]. Like SFTs, the clinical outcome of extra-pleural SFTs is unpredictable. This is confirmed for 
the prostatic location through the analysis of the 17 cases reported with available follow-up. Only 1 patient displayed a local relapse at 12 months from initial incomplete surgery [12]. Two patients died from postoperative complications on day 1 and from an unrelated cause at 7 months, respectively. None of the 14 other patients did relapse after a follow-up ranging from 2 months to 10 years, although several of them, including ours (large tumor size, cellular areas and foci of necrosis), displayed aggressiveness criteria. The only patient who relapsed was the one with incomplete initial surgery [12]. For many authors, the complete resection of the tumor, whatever its pleural or extra-pleural location, is the most important factor predictive of clinical outcome, implying that the malignant potential of SFTs should be assessed according to both the histological aggressiveness criteria and tumor resectability, keeping in mind that histologically benign and completely resected tumors still have long-term malignant potential. Of course, given the scarcity of reported prostatic SFT cases and the lack of long-term follow-up, no conclusion can be drawn. Additional cases with long-term follow-up are required to better establish prognosis of prostatic SFTs and reliable prognostic criteria.

Given the scarcity of prostatic SFT, data on optimal treatment are obviously limited. Given the possible aggressive behavior and the uncertainty regarding the prognostic factors, prostate SFTs should be removed by complete excision with negative margins, then carefully followed-up for tumor recurrence. Surgery consists generally in a nervesparing radical prostatectomy, especially in younger men, aiming at preserving sexual and urinary functions. Associated cystectomy should be reserved to the cases of bladder involvement like ours, where involvement was suspected during surgery. SFTs are relatively insensitive to chemotherapy and radiotherapy [19]. In the literature, one patient received adjuvant radiation therapy after $\mathrm{R} 2$ resection.

\section{Conclusion}

We report and add an additional case of prostatic SFT to the literature. It is likely that these tumors have a clinical behavior similar to other SFTs. Complete surgical excision with negative margins is the best chance for cure. Although the clinical outcome of prostatic SFT seems favorable, it remains difficult to predict, and postoperative careful long-term follow-up for tumor relapse and possible malignant transformation is warranted regardless the histological criteria of aggressiveness.

\section{Acknowledgements}

Our work is supported by the Institut Paoli-Calmettes and the University of Mediterranea. We thank our patient who kindly gave his consent for this publication.

\section{Disclosure Statement}

The authors declare no conflict of interest. 
Table 1. Twenty-two cases of prostatic SFT reported in the literature

\begin{tabular}{|c|c|c|c|c|c|c|c|c|c|c|c|c|}
\hline Ref. & $\begin{array}{l}\text { Age } \\
\text { years }\end{array}$ & Clinical symptoms & $\begin{array}{l}\text { Serum } \\
\text { PSA }\end{array}$ & HypoG & Biopsy & Treatment & $\begin{array}{l}\text { Pathol. } \\
\text { margins }\end{array}$ & $\begin{array}{l}\text { Pathol. } \\
\text { tumor } \\
\text { size, cm }\end{array}$ & $\begin{array}{l}\text { Ne- } \\
\text { cro- } \\
\text { sis }\end{array}$ & $\begin{array}{l}\text { Mitotic } \\
\text { count (per } \\
10 \mathrm{HPF})\end{array}$ & $\begin{array}{l}\text { Cellu- } \\
\text { larity }\end{array}$ & Outcome \\
\hline [6] & 72 & $\begin{array}{l}\text { obstructive urinary } S \\
\text { and pelvic pressure }\end{array}$ & NA & no & no & TUR & NA & NA & no & $<2$ & low & NA \\
\hline [10] & 42 & $\begin{array}{l}\text { obstructive urinary } \\
\text { and rectal S }\end{array}$ & NA & NA & no & $\mathrm{CP}$ & NA & 14 & yes & NA & NA & NR 10 months \\
\hline [5] & 59 & obstructive urinary $S$ & normal & NA & yes & observation & NA & NA & NA & NA & NA & NA \\
\hline [13] & $65^{*}$ & obstructive urinary $S$ & NA & NA & no & $\mathrm{CP}+\mathrm{RT}$ & $\mathrm{R} 2$ & 'large' & yes & NA & high & NR 2 months \\
\hline [8] & 57 & $\begin{array}{l}\text { none (rectal } \\
\text { examination) }\end{array}$ & normal & no & yes & $\mathrm{P}$ & R0 & 10 & no & $<1$ & low & NR 15 months \\
\hline [8] & 73 & obstructive urinary $S$ & normal & no & no & $\mathrm{P}$ & NA & 6 & no & 4 & high & NR 21 months \\
\hline [9] & 42 & obstructive urinary $S$ & normal & NA & yes & $\mathrm{P}$ & R0 & NA & NA & 2 & high & NR 18 months \\
\hline [4] & 21 & obstructive urinary $S$ & NA & NA & yes & $\begin{array}{l}\text { enucleation } \\
\text { (24-mm nodule) }\end{array}$ & NA & NA & NA & 0 & NA & NA \\
\hline [11] & 87 & $\begin{array}{l}\text { obstructive urinary } \mathrm{S} \\
\text { and hematuria }\end{array}$ & normal & NA & no & $\begin{array}{l}\text { emergency } \\
\text { hemostatic P }\end{array}$ & $\mathrm{R} 1$ & $>9$ & yes & 15 & high & $\begin{array}{l}\text { Death (day } 1 \\
\text { postoperative- } \\
\text { ly) }\end{array}$ \\
\hline [12] & 35 & obstructive urinary S & normal & NA & yes & enucleation & $\mathrm{R} 1$ & 5.2 & no & NA & low & $\begin{array}{l}\text { Local relapse } \\
12 \text { months }\end{array}$ \\
\hline [14] & $\begin{array}{l}\text { medi- } \\
\text { an: } \\
65^{* *} \\
\text { (range } \\
46-75 \text { ) }\end{array}$ & obstructive urinary S & NA & no & NA & $\begin{array}{l}\text { TUR (1 pt); } \\
\text { P (4 pts); CP } \\
(2 \text { pts); pelvic } \\
\text { exenteration } \\
(2 \text { pts); } \\
\text { enucleation (1 } \\
\text { pt) }\end{array}$ & NA & $\begin{array}{l}\text { median: } \\
10.5^{* *} \\
\text { (range } \\
8.5-15 \text { ) }\end{array}$ & yes & $\begin{array}{l}0 \\
(5 \mathrm{pts}) ; \\
3-5 \\
(5 \mathrm{pts})\end{array}$ & NA & $\begin{array}{l}\text { NA ( } 4 \text { pts) } \\
\text { death }(7 \\
\text { months, } \\
\text { unrelated } \\
\text { cause: } 1 \text { pt) NR } \\
1 \text { to } 10 \text { years ( } 5 \\
\text { pts) }\end{array}$ \\
\hline [7] & 37 & obstructive urinary S & NA & NA & yes & enucleation & $\mathrm{R} 1$ & 10 & NA & 1 & high & NR 24 months \\
\hline$[3]$ & 60 & obstructive urinary S & normal & NA & yes & $\mathrm{P}$ & R0 & 8 & no & 1 & low & NR 6 months \\
\hline $\begin{array}{l}\text { Our } \\
\text { case }\end{array}$ & 60 & obstructive urinary $S$ & normal & no & yes & $\mathrm{CP}$ & R0 & 15 & yes & 4 & high & NR 28 months \\
\hline
\end{tabular}

${ }^{*}$ This case is also included in [14]; ${ }^{* *} 10$ cases, including the case reported in [13]. S = Symptoms; NA = not available; HypoG = hypoglycemia; $\mathrm{TUR}$ = transurethral resection; $\mathrm{CP}$ = cystoprostatectomy; $\mathrm{P}=$ prostatectomy; $\mathrm{RT}$ = radiotherapy; $\mathrm{NR}=$ no relapse . 

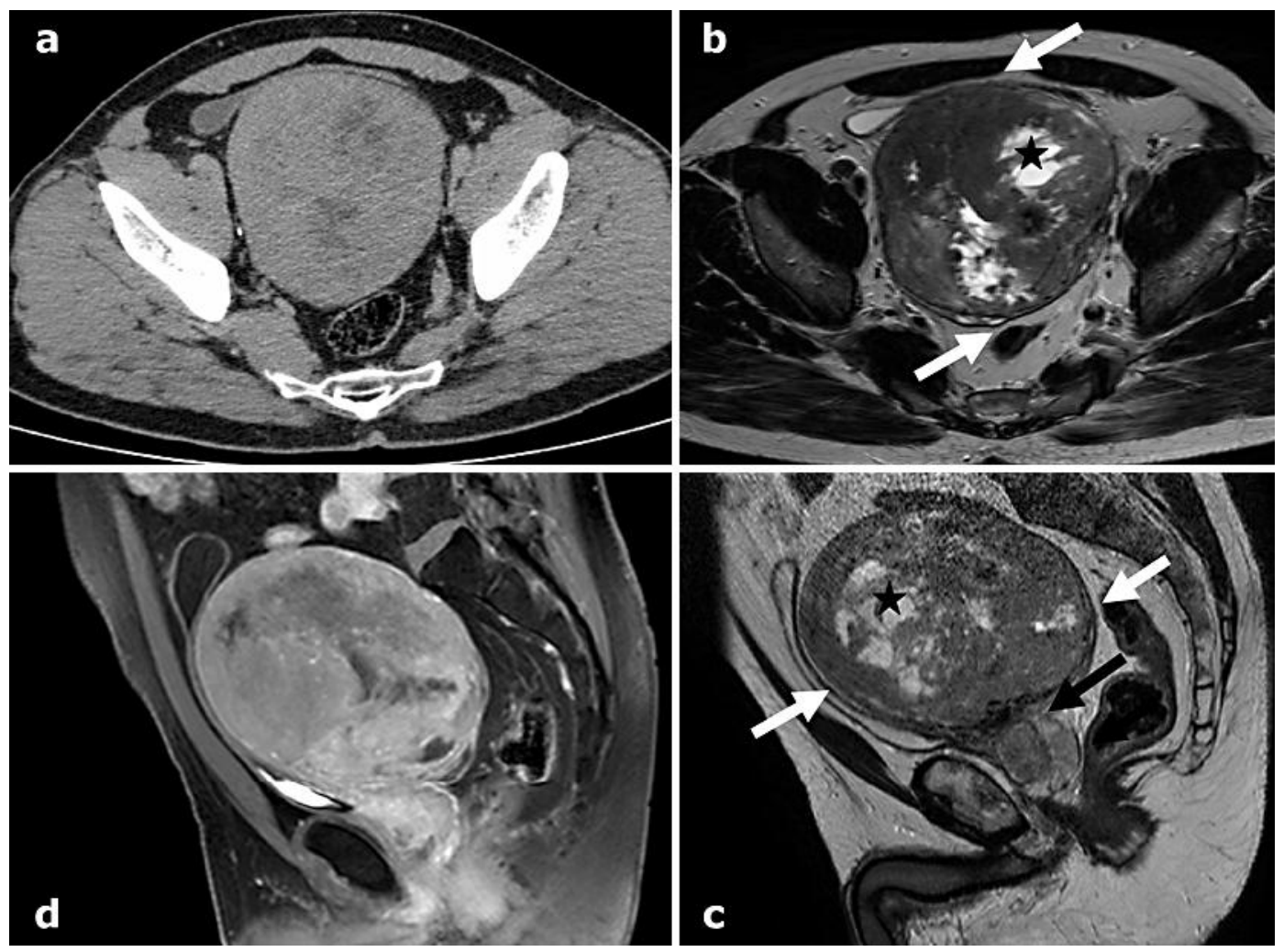

Fig. 1. Imaging of prostatic SFT. Pelvic axial CT-scan (a) detecting a medial massive mass lesion in pelvic and hypogastric regions. Axial (b) and sagittal (c) T2-weighted magnetic resonance image showing an inhomogeneous mass lesion with necrotic areas (stars), arising from prostatic basis

(black arrow), with a distinct margin between the mass as well as between the posterior wall of the bladder and the anterior wall of the rectum (white arrows). Sagittal T1-weighted injected magnetic resonance image (d) shows an inhomogeneous and highly contrast-enhanced mass. 

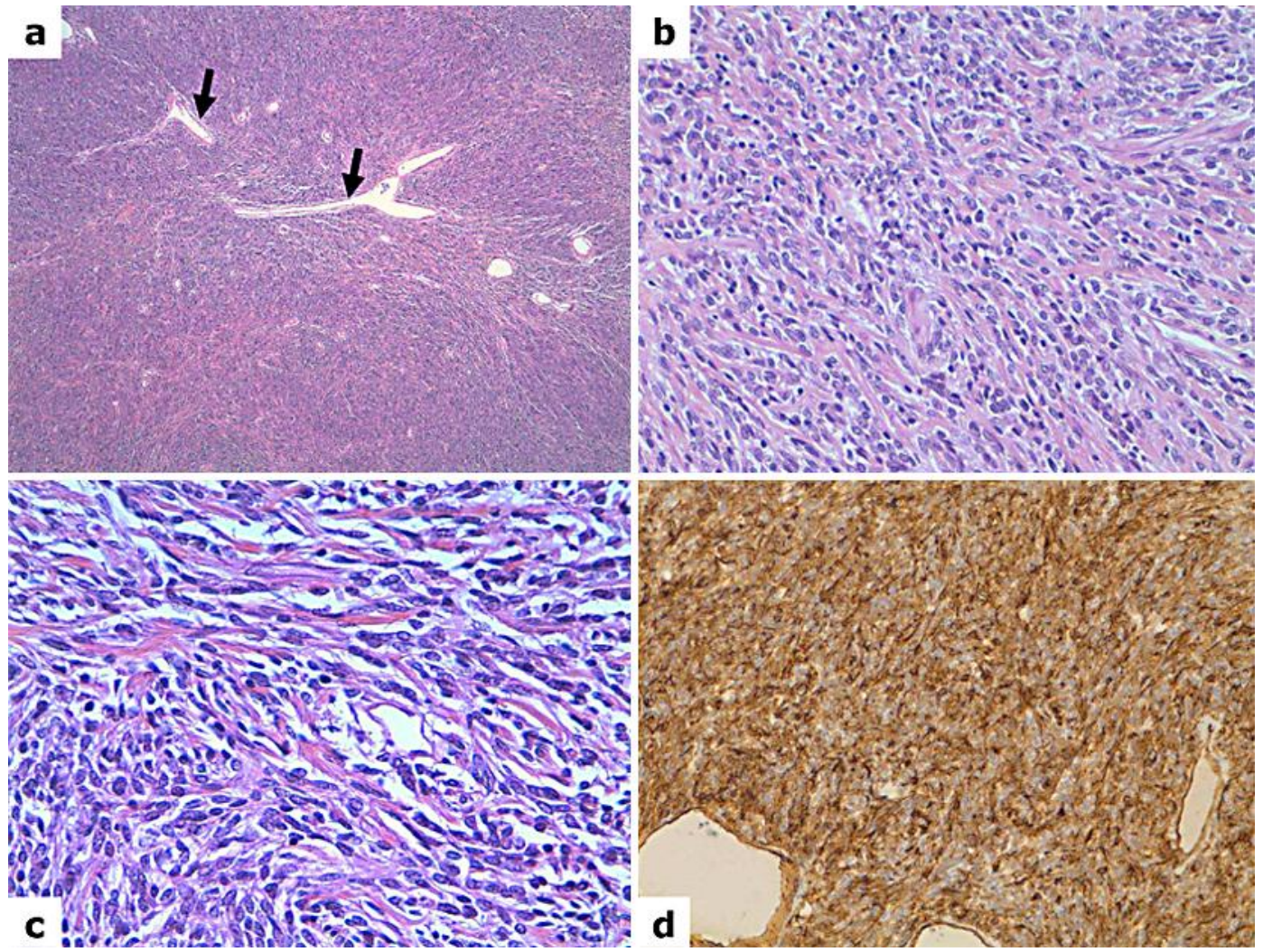

Fig. 2. Prostatic SFT: histological aspects. a Low-power view of a highly cellular area with characteristic 'staghorn' vessels (black arrows) (HE staining, original magnification $\times 40$ ). $\mathbf{b}$ An area of lower cellularity: cells are mixed with collagen bundles (HE, original magnification $\times 200$ ). c Highpower view showing oval to fusiform cells with scant atypias (HE, original magnification $\times 400$ ). $\mathbf{d}$ Tumor cells strongly express CD34 (CD34 immunodetection, original magnification $\times 100$ ).

\section{References}

1 Robinson LA: Solitary fibrous tumor of the pleura. Cancer Control 2006;13:264-269.

2 Vallat-Decouvelaere AV, Dry SM, Fletcher CD: Atypical and malignant solitary fibrous tumors in extrathoracic locations: evidence of their comparability to intra-thoracic tumors. Am J Surg Pathol 1998;22:1501-1511.

-3 Galosi AB, Mazzucchelli R, Scarpelli M, Lopez-Beltran A, Cheng L, Muzzonigro G, Montironi R: Solitary fibrous tumour of the prostate identified on needle biopsy. Eur Urol 2009;56:564-567.

4 Grasso M, Blanco S, Franzoso F, Lania C, Di Bella C, Crippa S: Solitary fibrous tumor of the prostate. J Urol 2002;168:1100.

5 Kelly PM, Baxter GM: Solitary fibrous tumour of the prostate. Br J Radiol 1998;71:1086-1088.

-6 Mentzel T, Bainbridge TC, Katenkamp D: Solitary fibrous tumour: clinicopathological, immunohistochemical, and ultrastructural analysis of 12 cases arising in soft tissues, nasal cavity and nasopharynx, urinary bladder and prostate. Virchows Arch 1997;430:445-453.

7 Nair B, Nambiar A, Hattangadi SB, Sukumar S, Saifuddin MS: Solitary fibrous tumour of prostate: evaluation and management of a rare tumour. Scand J Urol Nephrol 2007;41:442-444.

-8 Pins MR, Campbell SC, Laskin WB, Steinbronn K, Dalton DP: Solitary fibrous tumor of the prostate a report of 2 cases and review of the literature. Arch Pathol Lab Med 2001;125:274-277.

$\checkmark 9$ Sekine H, Ohya K, Kojima S, Mizuguchi K: Solitary fibrous tumor of the prostate. Int J Urol 2001;8:137138. 
10 Takeshima Y, Yoneda K, Sanda N, Inai K: Solitary fibrous tumor of the prostate. Pathol Int 1997;47:713717.

11 Vodovnik A, Rogawski K, Bolton JF: A case of malignant solitary fibrous tumor of the prostate. Pathol Int 2005;55:807-808.

-12 Oguro S, Tanimoto A, Jinzaki M, Akita H, Yashiro H, Okuda S, Kuribayashi S, Kameyama K, Mukai M: Imaging findings of solitary fibrous tumor of the prostate: a case report. Magn Reson Imaging 2006;24:673-675.

13 Westra WH, Grenko RT, Epstein J: Solitary fibrous tumor of the lower urogenital tract: a report of five cases involving the seminal vesicles, urinary bladder, and prostate. Hum Pathol 2000;31:63-68.

14 Herawi M, Epstein JI: Solitary fibrous tumor on needle biopsy and transurethral resection of the prostate: a clinicopathologic study of 13 cases. Am J Surg Pathol 2007;31:870-876.

15 England DM, Hochholzer L, McCarthy MJ: Localized benign and malignant fibrous tumors of the pleura. A clinicopathologic review of 223 cases. Am J Surg Pathol 1989;13:640-658.

16 Harrison-Phipps KM, Nichols FC, Schleck CD, Deschamps C, Cassivi SD, Schipper PH, Allen MS, Wigle DA, Pairolero PC: Solitary fibrous tumors of the pleura: results of surgical treatment and long-term prognosis. J Thorac Cardiovasc Surg 2009;138:19-25.

17 Moran CA, Suster S, Koss MN: The spectrum of histologic growth patterns in benign and malignant fibrous tumors of the pleura. Semin Diagn Pathol 1992;9:169-180.

18 Hanau CA, Miettinen M: Solitary fibrous tumor: histological and immunohistochemical spectrum of benign and malignant variants presenting at different sites. Hum Pathol 1995;26:440-449.

19 Park MS, Araujo DM: New insights into the hemangiopericytoma/solitary fibrous tumor spectrum of tumors. Curr Opin Oncol 2009;21:327-331. 